\title{
REGRESI LINEAR DAN DKL 3.01 UNTUK ANALISIS PEMBANGUNAN PEMBANGKIT LISTRIK MINIHIDRO MOBUYA 3X1000 KW DI SULAWESI UTARA
}

\author{
Taufik Hidayatullah $^{1}$, Pressa Perdana ${ }^{2}$ \\ ${ }^{1}$ Jurusan Teknik elektro \\ Institut Teknologi Sepuluh Nopember (ITS) \\ Surabaya, Indonesia \\ ${ }^{2}$ Jurusan Teknik Elektro \\ Universitas Muhammadiyah Gresik \\ Gresik, Indonesia \\ press_a@elect-eng.its.ac.id
}

\begin{abstract}
ABSTRAK
Distribusi Listrik saat sekarang belum sepenuhnya menjangkau daerah-daerah terpencil di Indonesia. Padahal listrik atau penerangan sangat dibutuhkan oleh daerah tersebut agar daerah tersebut tidak ketinggalan dalam memperoleh informasi yang bertujuan untuk memajukan daerah tersebut dan dapat meningkatan produktifitas masyarakatnya. Oleh karena itu untuk memenuhi kebutuhan listrik pada daerah terpencil perlu diciptakan alat yang dapat menjangkau tempat terpencil dengan harga murah dan ramah lingkungan.

Kebutuhan energi listrik di kabupaten Bolaang Mangondow, Sulawesi utara dari tahun ke tahun semakin meningkat seiring dengan meningkatnya kegiatan pembangunan serta kebutuhan domestik, sementara kapasitas pembangkit listrik yang ada adalah tenaga Diesel yang diharapkan mensuplai energi listrik di daerah tersebut mengalami penurunan. Pada tahun 2000 jumlah penduduk kabupaten Bolaang Mongondow sebesar 429.475 jiwa. Dari jumlah tersebut sebagian besar penduduk masih masuk kedalam kategori usia muda. Jumlah penduduk tahun 2005 adalah sebesar 479.841 jiwa. Angka ini merupakan hasil pendataaan registrasi penduduk tahun 2005. laju pertumbuhan penduduk rata-rata sebesar 1,47 \% per tahun selama periode 1991 - 2005. Pertumbuhan penduduk tersebut tergolong tinggi karena penduduknya kebanyakan masih tergolong usia produktif.

Melihat topografi daerah yang sebagian besar gunung dan hutan dapat dipastikan mempunyai potensi air yang banyak. Untuk mengatasi tingginya permintaan akan kebutuhan listrik tersebut, maka muncul konsep pembangkit listrik yang bertumpu pada masyarakat di daerah terpencil. Konsep ini berbasis pada teknologi Pembangkit Listrik Tenaga Minihidro (PLTM). Istilah minihidro biasanya dipakai untuk pembangkit listrik yang menghasilkan output $3000 \mathrm{~kW}$. PLTM merupakan salah satu alternatif solusi yang dapat menembus keterbatasan akses transportasi, teknologi hingga biaya.
\end{abstract}

Kata kunci: Minihidro, DKL 3.01, Regresi. 


\begin{abstract}
Power Distribution time now have not fully reach remote areas in Indonesia. Though electricity or lighting is needed by the region so that the region does not lag in obtaining the information that aims to promote the area and can increase the productivity of its people. Therefore, to meet the needs of electricity in remote areas is necessary to create a tool that can reach out to remote sites with low prices and friendly environment.

Electric energy needs in the district Bolaang Mongondow, North Sulawesi from year to year increase along with the increase in development activities as well as domestic demand, while the capacity of existing power plants Diesel power is expected to supply electricity in the area has decreased. In 2000 the district population of 429 475 inhabitants Bolaang Mongondow. Of these the majority of the population is still in the category of young age. The population in 2005 was $\$ 479841$ inhabitants. This figure is the result of population registration Data Collection in 2005. The population growth rate by an average of $1.47 \%$ per annum during the period 1991 2005. The population growth is high because most of the population is still relatively productive age.

See the topography of the area that most of the mountain and forest certainly has the potential of water. To cope with the high demand for electricity needs, then came the concept of power that relies on communities in remote areas. This concept is based on the technology of mini-hydro Power Plant (micro power plants). The term is usually used for mini-hydro power plants that generate $1000 \mathrm{~kW}$ output. Micro power is one alternative solution that can break through the limitations of access to transport, technology up costs.
\end{abstract}

Keywords- Minihidro, DKL 3.01, Regresi. 


\section{PENDAHULUAN}

Distribusi Listrik saat sekarang belum sepenuhnya menjangkau daerah-daerah terpencil di Indonesia. Padahal listrik atau penerangan sangat dibutuhkan oleh daerah tersebut agar daerah tersebut tidak ketinggalan dalam memperoleh informasi yang bertujuan untuk memajukan daerah tersebut dan dapat meningkatan produktifitas masyarakatnya. Oleh karena itu untuk memenuhi kebutuhan listrik pada daerah terpencil perlu diciptakan alat yang dapat menjangkau tempat terpencil dengan harga murah dan ramah lingkungan

Berdasarkan pasal 4 perpres 71 tahun 2006: Pembangunan pembangkit tenaga listrik dilakukan dengan mengutamakan penggunaan produk dalam negeri sepanjang kualitasnya memenuhi syarat dan harganya bersaing. Maka diupayakan pembangunan pembangkit ini dapat memanfaatkan hasil alam Indonesia.

Masyarakat Sulawesi Utara yang hidup di daerah terpencil sulit dijangkau oleh PLN menjadi suatu permasalahan tersendiri sedangkan kebutuhan energi listrik di semakin meningkat. Hal ini menyebabkan terjadinya kekuranga listrik di daerah tersebut. Dengan meningkatnya kebutuhan akan listrik, sarana pembangkitan listrik harus ditambah agar tidak terjadi krisis listrik di daerah Sulawesi utara khususnya di bupaten bolaang mongondow. [1,2]

Dalam perencanaan pembangunan pembangkit ini, salah satu hal yang sangat dibutuhkan dalam perencanaannya adalah pertumbuhan kelistrikan penduduk. Dengan mengetahui pertumbuhan kelistrikan penduduk, maka kita dapat memperkirakan daya pembangkit yang akan kita rencanakan dan sampai kapan pembangkit tersebut mampu memenuhi kebutuhan kelistrikan pada suatu daerah.

Pertumbuhan kelistrikan pada suatu daerah, sangat bergantung banyak faktor. Dalam penelitian ini akan digunakan regresi linear dan metode DKL 3.01 dalam memperkirakan pertumbuhan kelistrikan sampai 20 tahun mendatang.

PLTM adalah pembangkit listrik dengan kapasitas daya output sekitar $1000 \mathrm{~kW}$. Pada beberapa PLTM bak pengendap yang berfungsi untuk mengendapkan dan memisahkan partikelpartikel pasir dari air, tidak digunakan. Tujuannya adalah untuk menghemat biaya konstruksi dan alasan fungsi pengendap dan pemisah partikel pasir dari air dapat dilakukan oleh bak penenang (headtank). Bak penenang mengatur perbedaan air antara sebuah penstock dan saluran pembawa (headrace). Selain itu juga berfungsi sebagai pemisah akhir kotoran dalam air seperti pasir, daun-daunan dan kayu-kayuan. Saluran pembawa (headrace) merupakan saluran yang menghubungkan bak pengendap dan bak penenang. Saluran pembawa ini biasanya mengikuti kontur sisi bukit untuk menjaga elevasi dari air yang disalurkan. Saluran pembawa ini umumnya menggunakan sistem terbuka supaya menghemat biaya pengeluaran akibat penstock. [3-5]

Peramalan kebutuhan listrik adalah untuk mengetahui akan kebutuhan listrik di tahun yang akan dating dapat dilakukan dengan berbagai cara salah satunya dengan metode DKL 3,01 dan metode regresi linear. metode DKL 3,01 ini merupakan metode menghitung peramalan kebutuhan listrik tiap pelanggan dengan memperhitungkan rasio elektrifikasi tiap pelanggan. Metode tersebut paling banyak digunakan oleh PLN.

Model yang digunakan dalam metode DKL 3.01 untuk menyusun perkiraan adalah model sektoral. Perkiraan kebutuhan tenaga listrik model sektoral digunakan untuk menyusun perkiraan kebutuhan tenaga listrik pada tingkat wilayah/distribusi. Metodologi yang digunakan pada model sektoral adalah metode gabungan antara kecenderungan, ekonometri dan analitis. Pendekatan yang digunakan dalam menghitung kebutuhan listrik adalah dengan mengelompokkan pelanggan menjadi empat sektor yaitu : 
1. Sektor Rumah Tangga

2. Sektor Bisnis

3. Sektor Publik

4. Sektor Industri

\section{REGRESI LINEAR [6]}

Secara umum, regresi merupakan sebuah alat statistik yang memberikan gambaran tentang pola hubungan antara dua variabel atau lebih.. Dalam analisis regresi dikenal 2 jenis variabel yaitu:

1. Variabel Respon atau variabel dependen yaitu variabel yang keberadaannya dipengaruhi oleh variabel lainnya dan dinotasikan dengan variabel .

2. Variabel Prediktor atau variabel independen yaitu variabel yang bebas (tidak dipengaruhi oleh variabel lainnya) dan dinotasikan dengan Untuk mempelajari hubugan - hubungan antara variabel bebas maka regresi linier terdiri dari dua bentuk, yaitu:

1. Analisis regresi sederhana (simple analysis regresi)

2. Analisis regresi berganda (Multiple analysis regresi).

\section{REGRESI LINIER BERGANDA [6]}

Suatu persamaan regresi linier yang mempunyai dua variabel bebas $\mathrm{X}$ atau lebih, dan satu variabel terikat $\mathrm{Y}$ akan membentuk suatu persamaan regresi yang disebut persamaan regresi linier berganda (multiple regression). Model persamaan regresi linier berganda hampir sama dengan model regresi linier sederhana, letak perbedaanya hanya pada banyak variabel bebasnya.

Model untuk taksiran dari persamaan regresi linier ganda atas $X_{1}, X_{2}, \ldots, X_{n}$ sebagai variabel bebasnya adalah sebagai berikut:

$$
\hat{Y}=b_{0}+b_{1} X_{1}+b_{2} X_{2}+\ldots+b_{k} X_{k}
$$

Dimana:

$\hat{\mathrm{Y}}=$ Variabel Bagi taksiran Nilai $\mathrm{Y}$

$\mathrm{b}_{0}=$ Taksiran bagi parameter konstanta $\beta_{0}$

$\mathrm{b}_{1}, \mathrm{~b}_{2}, \mathrm{~b}_{3}=$ Taksiran bagi parameter konstanta $\beta_{1}, \beta_{2}, \beta_{3}, \ldots \ldots, \beta_{\mathrm{k}}$
Sama seperti mencari nilai a dan b pada model regresi linier sederhana, maka pada regresi linier berganda pun memerlukan $\mathrm{n}$ buah pasang data $X$ dan $Y$. Untuk mencari harga-harga $b_{0}, b_{1}$, $b_{2}, \ldots . \quad b_{k}$ dari regresi linier berganda dapat menggunakan matriks sebagai berikut :

Tabel 1. Data Hasil Pengamatan dari $n$ Responden $\left(\mathrm{X}_{1}, \mathrm{X}_{2}, \mathrm{X}_{3}, \ldots . \mathrm{Y}\right)$

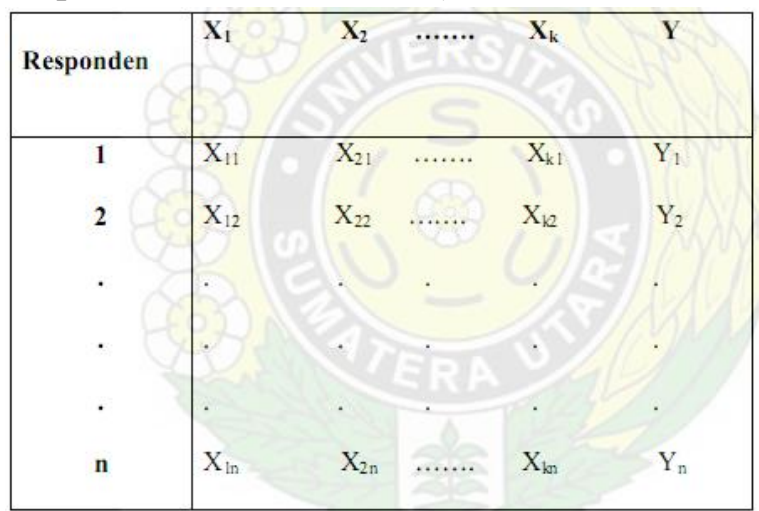

Dari tabel 1 dapat dilihat bahwa $Y_{1}$ berpasangan dengan $X_{11}, X_{21}, \ldots, X_{k 1}$, data $Y_{2}$ berpasangan dengan $X_{12}, X_{22}, \ldots . ., X_{k 2}$ dan umumnya data $Y_{n}$ berpasangan dengan $X_{1 n}$ $, \mathrm{X}_{2 \mathrm{n}}, \ldots, \mathrm{X}_{\mathrm{kn}}$.

Persamaan regresi berganda dengan dua variabel bebas $\mathrm{X} 1, \mathrm{X} 2$ ditaksir oleh :

$$
Y=b_{0}+b_{1} X_{1}+b_{2} X_{2}
$$

Dan diperoleh tiga persamaan normal yaitu:

$$
\begin{array}{ll}
\sum \mathrm{Y}_{\mathrm{i}} & =\mathrm{b}_{0} \mathrm{n}+\mathrm{b}_{1} \sum \mathrm{X}_{1 \mathrm{i}}+\mathrm{b}_{2} \sum \mathrm{X}_{2 \mathrm{i}} \\
\sum \mathrm{Y}_{\mathrm{i}} \sum \mathrm{X}_{1 \mathrm{i}} & =\mathrm{b}_{0} \sum \mathrm{X}_{1 \mathrm{i}}+\mathrm{b}_{1} \sum \mathrm{X}_{1 \mathrm{i}}{ }^{2}+\mathrm{b}_{2} \sum \mathrm{X}_{1 \mathrm{i}} \mathrm{X}_{2 \mathrm{i}} \\
\sum \mathrm{Y}_{\mathrm{i}} \sum \mathrm{X}_{2 \mathrm{i}} & =\mathrm{b}_{0} \sum \mathrm{X}_{2 \mathrm{i}}+\mathrm{b}_{1} \sum \mathrm{X}_{2 \mathrm{i}} \mathrm{X}_{1 \mathrm{i}}+\mathrm{b}_{2} \sum \mathrm{X}_{2 \mathrm{i}}{ }^{2}
\end{array}
$$

Sehingga dalam bentuk matriks dapat dituliskan :

$$
\left[\begin{array}{c}
\sum Y_{i} \\
\sum Y_{i} X_{1 i} \\
\sum Y_{i} X_{2 i}
\end{array}\right]=\left[\begin{array}{ccc}
n & \sum X_{1 i} & \sum X_{2 i} \\
\sum X_{1 i} & \sum X_{1 i} & \sum X_{1 i} X_{2 i} \\
\sum X_{2 i} & \sum X_{1 i} X_{2 i} & \sum X_{2 i}
\end{array}\right] x\left[\begin{array}{l}
b_{0} \\
b_{1} \\
b_{2}
\end{array}\right]
$$

Dengan :

$\hat{\mathrm{Y}} \quad=$ variabel terikat (nilai duga $\mathrm{Y}$ )

$\mathrm{X}_{1}, \mathrm{X}_{2}=$ variabel bebas

$b_{0}, b_{1}, b_{2}$ dan $b_{3}=$ koefisien regresi linier berganda

$\mathrm{b}_{0} \quad=$ nilai $\mathrm{Y}$, apabila $\mathrm{X}_{1}=\mathrm{X}_{2}=0$ 
$\mathrm{b}_{1} \quad=$ besarnya kenaikan/penurunan $\mathrm{Y}$ dalam satuan, jika $X_{1}$ naik/ turun satu satuan dimana $\mathrm{X}_{2}$ konstan.

$\mathrm{b}_{2} \quad=$ besarnya kenaikan/penurunan $\mathrm{Y}$ dalam satuan, jika $X_{2}$ naik/ turun satu satuan dimana $\mathrm{X}_{1}$ konstan.

Bila dalam suatu keadaan terdapat 4 variabel, yaitu satu variabel tak bebas (dependent variabel) dan tiga variabel bebas (independent variabel) maka akan terbentuk matriks $4 \mathrm{x} 4$.

Harga - harga $b_{0}, b_{1}, b_{2}$ dan $b_{3}$ yang telah didapat kemudian disubstitusikan ke dalam persamaan sehingga diperoleh model regresi linier berganda $\mathrm{Y}$ atas $\mathrm{X}_{1}, \mathrm{X}_{2}, \mathrm{X}_{3}$.

Dalam persamaan model regresi linier yang diperoleh, maka antara nilai $\mathrm{Y}$ dengan $\hat{\mathrm{Y}}$ akan menimbulkan perbedaan hasil yang sering disebut sebagai kekeliruan Ukuran tersebut dapat dihitung oleh kekeliruan baku taksiran $S_{\text {y.12...k }}^{2}$ ,yang dapat ditentukan dengan rumus :

$s_{y .12 \ldots k}^{2}=\frac{\sum(Y-Y)^{2}}{n-k-1}$

Dengan :

$\mathrm{Y}_{\mathrm{i}}=$ nilai data hasil pengamatan

$\hat{Y}=$ nilai hasil regresi

$\mathrm{n}=$ ukuran sampel

$\mathrm{k}$ = banyak variabel bebas

\section{KONDISI KETENAGALISTRIKAN DI SULAWESI UTARA SAAT INI}

Kondisi listrik di Sulawesi Utara mengalami pertumbuhan yang cukup besar dan perlu segera dibangun pembangkit baru. Sejak beberapa tahun terakhir, seiring dengan pertumbuhan penduduk, kawasan pemukiman, industri dan ekonomi, Sulawesi Utara mengalami krisis energi listrik.

Berdasarkan data statistik PLN tahun 2008 kapasitas daya yang terpasang dan daya mampu di Sulawesi utara yang disediakan PLN Sulawesi Utara adalah 142 MW dan daya terpasang sebesar 224.33 MW. Sementara kebutuhan pelanggan di wilayah ini pada beban puncak pmencapai 139,10 MW. Artinya, margin standar keandalan sistem tidak tercapai karena selisih daya dan kebutuhan sangat kecil. Diperlukan anggaran yang besar agar keandalan sistem tercapai dan itu diluar kemampuan PLN. Pihak swasta bisa saja membantu pendanaan pembangkit listrik kita dengan berbagai skema yang memungkinkan. Selain itu, beberapa masalah yang kerap mengganggu pasokan listrik di Sulawesi Utara diantaranya:Perbaikan atau overhaul mesin PLTU yang harus dilakukan setiap tahun. Akibatnya, saat mesin diperbaiki, kemampuan PLN jauh berkurang menyediakan listrik. [2]

Tabel 2. Data Setiap tahun kondisi listrik di Sulawesi Utara

\begin{tabular}{|c|c|c|c|}
\hline Tahun & $\begin{array}{c}\text { Daya } \\
\text { Terpasang } \\
\text { (MW) }\end{array}$ & $\begin{array}{c}\text { Daya } \\
\text { mampu } \\
\text { (MW) }\end{array}$ & $\begin{array}{c}\text { Beban } \\
\text { puncak } \\
\text { (MW) }\end{array}$ \\
\hline 2004 & 178.08 & 156.58 & 136.79 \\
\hline 2005 & 181.94 & 147.68 & 140.49 \\
\hline 2006 & 186.56 & 139.28 & 144.29 \\
\hline 2007 & 218.77 & 133.79 & 146.60 \\
\hline 2008 & 224.33 & 142.00 & 139.10 \\
\hline
\end{tabular}

(Sumber : Statistik PLN)

\section{PROYEKSI PERTUMBUHAN PENDUDUK DAN PASOKAN TENAGA LISTRIK}

Dari perhitungan DKL 3,01 dapat dibuat tabel tentang pertumbuhan penduduk dan konsumsi energi listrik di Sulawesi Utara. [7]

Jumlah pelanggan listrik total dapat dihitung dengan cara menjumlahkan seluruh pelanggan per sektor. Hasil dari perhitungan tersebut dapat dilihat pada Tabel 3

Tabel 3. Proyeksi Jumlah Pelanggan Listrik Total per Kelompok Pelanggan di Provinsi Sulawesi Utara

\begin{tabular}{|c|c|r|c|c|r|}
\hline $\begin{array}{c}\text { Tahu } \\
\mathbf{n}\end{array}$ & $\begin{array}{c}\text { Tang } \\
\text { Tang } \\
\mathbf{a}\end{array}$ & $\begin{array}{c}\text { Bisni } \\
\mathbf{s}\end{array}$ & $\begin{array}{c}\text { Indust } \\
\text { ri }\end{array}$ & $\begin{array}{c}\text { Publi } \\
\mathbf{k}\end{array}$ & Total \\
\hline 2009 & $\begin{array}{r}36308 \\
2\end{array}$ & $\begin{array}{r}1307 \\
0\end{array}$ & 437 & 9440 & $\begin{array}{r}38602 \\
9\end{array}$ \\
\hline 2010 & 36656 & 1319 & & & 38980 \\
& 8 & 6 & 506 & 9531 & 1 \\
\hline 2011 & 37008 & 1332 & & & 39361 \\
\hline 2012 & 7 & 3 & 585 & 9622 & 7 \\
\hline 2013 & 377227 & 13580 & 783 & 9807 & 7 \\
\hline
\end{tabular}




\begin{tabular}{|r|r|r|r|r|r|} 
& & & & 40536 \\
2014 & 380848 & 13710 & 907 & 9902 & 7 \\
\hline 2015 & 384504 & 13842 & 1049 & 9997 & 40939 \\
\hline 2016 & 388195 & 13975 & 1214 & 10093 & 7 \\
\hline 2017 & 391922 & 14109 & 1404 & 10190 & 5 \\
\hline 2018 & 395685 & 14244 & 1625 & 10288 & 2 \\
\hline 2019 & 399483 & 14381 & 1880 & 10387 & 1 \\
\hline 2020 & 403318 & 14519 & 2175 & 10486 & 8 \\
\hline 2021 & 407190 & 14658 & 2517 & 10587 & 264 \\
\hline 2022 & 411099 & 14799 & 2912 & 10688 & 8 \\
\hline 2023 & 415045 & 14941 & 3369 & 10791 & 6 \\
\hline
\end{tabular}

Kebutuhan atau konsumsi energi listrik total dapat dihitung dengan menjumlahkan konsumsi energi per sektor. Sehingga konsumsi energi total adalah sebagai berikut

Tabel 4. Proyeksi Konsumsi Energi Listrik per Kelompok Pelanggan (GWh) Sulawesi Utara dengan Metode DKL 3.01

\begin{tabular}{|c|c|c|c|c|c|}
\hline $\begin{array}{c}\text { Tah } \\
\text { un }\end{array}$ & $\begin{array}{c}\text { Rumah } \\
\text { Tangg }\end{array}$ & Bisnis & $\begin{array}{c}\text { Industr } \\
\mathbf{~}\end{array}$ & $\begin{array}{c}\text { Publi } \\
\mathbf{k}\end{array}$ & Total \\
\hline 2009 & 421.18 & 213.77 & 88.35 & 29.67 & 752.97 \\
\hline 2010 & 425.22 & 262.94 & 99.78 & 31.16 & 819.1 \\
\hline 2011 & 429.30 & 323.41 & 112.70 & 32.71 & 898.12 \\
\hline 2012 & 433.42 & 397.80 & 127.29 & 34.35 & 992.86 \\
\hline 2013 & 437.58 & 489.30 & 143.76 & 36.07 & 1106.71 \\
\hline 2014 & 441.78 & 601.83 & 162.37 & 37.87 & 1243.85 \\
\hline 2015 & 446.03 & 740.26 & 183.39 & 39.76 & 1409.44 \\
\hline 2016 & 450.31 & 910.52 & 207.13 & 41.75 & 1609.71 \\
\hline 2017 & 454.63 & 1119.94 & 233.94 & 43.84 & 1852.35 \\
\hline 2018 & 458.99 & 1377.52 & 264.23 & 46.03 & 2146.77 \\
\hline 2019 & & 1694.36 & & & 2504.52 \\
\hline
\end{tabular}

\begin{tabular}{|l|l|l|l|r|l|} 
& 463.40 & & 298.43 & 48.33 & \\
\hline 2020 & 467.85 & 2084.06 & 337.06 & 50.75 & 2939.72 \\
\hline 2021 & 472.34 & 2563.39 & 380.69 & 53.29 & 3469.71 \\
\hline 2022 & 476.88 & 3152.98 & 429.97 & 55.95 & 4115.78 \\
\hline 2023 & 481.45 & 3878.16 & 485.63 & 58.75 & 4903.99 \\
\hline
\end{tabular}

Tabel 5. Proyeksi Konsumsi Energi Listrik per Kelompok Pelanggan (GWh) Sulawesi Utara dengan Metode Regresi Linear

\begin{tabular}{|r|c|c|c|c|c|}
\hline $\begin{array}{c}\text { Tah } \\
\text { un }\end{array}$ & $\begin{array}{c}\text { Rumah } \\
\mathbf{a}\end{array}$ & Bisnis & $\begin{array}{c}\text { Industr } \\
\mathbf{i}\end{array}$ & $\begin{array}{c}\text { Publi } \\
\mathbf{k}\end{array}$ & Total \\
\hline 2009 & 421.49 & 182.03 & 77.17 & 30.31 & 711.01 \\
\hline 2010 & 440.73 & 196.57 & 80.57 & 31.95 & 749.81 \\
\hline 2011 & 460.14 & 211.21 & 84.45 & 33.58 & 789.39 \\
\hline 2012 & 479.74 & 225.98 & 88.98 & 35.24 & 829.94 \\
\hline 2013 & 499.54 & 240.86 & 94.19 & 36.91 & 871.50 \\
\hline 2014 & 519.51 & 255.85 & 100.29 & 38.62 & 914.28 \\
\hline 2015 & 539.69 & 271.08 & 107.28 & 40.33 & 958.37 \\
\hline 2016 & 560.05 & 286.42 & 115.39 & 42.05 & 1003.92 \\
\hline 2017 & 580.61 & 301.87 & 124.74 & 43.80 & 1051.03 \\
\hline 2018 & 601.37 & 317.44 & 135.61 & 45.56 & 1099.99 \\
\hline 2019 & 622.33 & 333.25 & 148.16 & 47.34 & 1151.07 \\
\hline 2020 & 643.49 & 349.16 & 162.67 & 49.12 & 1204.44 \\
\hline 2021 & 664.85 & 365.20 & 179.49 & 50.94 & 1260.48 \\
\hline 2022 & 686.42 & 381.46 & 198.92 & 52.75 & 1319.55 \\
\hline 202 & 708.1 & 397.8 & 221.4 & 54.61 & 1382.0 \\
\hline 3 & 9 & 4 & 0 & & 4 \\
\hline
\end{tabular}

\section{DAYA TERBANGKIT PLTM MOBUYA}

Rumus untuk menghitung daya output PLTM adalah:

$$
P=9,8 Q h(\mathrm{~kW})
$$

dimana:

$\mathrm{P}=$ daya output $(\mathrm{kW})$

$\mathrm{Q}=$ debit air (m3/detik)

$\mathrm{h}=$ head turbin $(\mathrm{m})$

Dalam proses konversi tenaga air menjadi energi listrik terdapat efisiensi, dimana efisiensi ini dipengaruhi oleh efisiensi turbin, efisiensi generator dan efisiensi saluran. Jika diasumsikan efisiensi turbin sebesar $90 \%$, efisiensi generator sebesar 90\%, dan efisiensi saluran 95\%, maka 
dengan adanya ketiga faktor efisiensi ini, persamaan daya output diatas menjadi :

$$
P=(0,9)(0,9)(0,95) 9,8 Q h(\mathrm{~kW})
$$

Dengan menggunakan persamaan diatas, maka dapat dihitung daya output untuk PLTM.jika digunakan debit rata-rata saluran dengan pembangkit beroperasi maksimum selama 270 hari dan 90 hari beropeasi seperti biasa, dimana selama 90 hari curah hujan paling rendah dimana debit air saluran juga minimum.maka menggunakan debit bulan mei tahun 2007 sehingga menghasilkan daya output dari PLTM. [8]

$$
\begin{aligned}
\mathrm{P} & =(0,9)(0,9)(0.95) 9,8 \times 5,21 \times 80 \\
& =7,5 \times 5,21 \times 80 \\
& =3,126 \mathrm{MW}
\end{aligned}
$$

Jadi dengan adanya PLTM Mobuya, daya total listrik di Sulawesi Utara menjadi 145.126 MW. Dengan demikian, energi total yang dihasilkan per tahun menjadi 1271.3 GWh.

\section{NERACA ENERGI KABUPATEN BOLAANG MANGONDOW}

Dengan adanya PLTM Mobuya pada tahun 2009, maka ketersediaan cadangan energi listrik

\begin{tabular}{|c|c|c|c|c|}
\hline \multicolumn{5}{|c|}{ Utara } \\
\hline Tahun & $\begin{array}{c}\text { Proyeksi } \\
\text { energi } \\
\text { dengan } \\
\text { DKL } \\
3.01\end{array}$ & $\begin{array}{c}\text { Kelebi } \\
\text { han } \\
\text { daya }\end{array}$ & $\begin{array}{c}\text { Proyeksi } \\
\text { energi } \\
\text { dengan } \\
\text { Regresi } \\
\text { linear }\end{array}$ & $\begin{array}{c}\text { Kelebihan } \\
\text { daya }\end{array}$ \\
\hline 2009 & 752.97 & 518.33 & 711.01 & 560.29 \\
\hline 2010 & 819.1 & 452.2 & 749.81 & 521.49 \\
\hline 2011 & 898.12 & 373.18 & 789.39 & 481.91 \\
\hline 2012 & 992.86 & 278.44 & 829.94 & 441.36 \\
\hline 2013 & 1106.71 & 164.59 & 871.5 & 399.8 \\
\hline 2014 & 1243.85 & 27.45 & 914.28 & 357.02 \\
\hline 2015 & 1409.44 & -138.14 & 958.37 & 312.93 \\
\hline 2016 & 1609.71 & -338.41 & 1003.92 & 267.38 \\
\hline 2017 & 1852.35 & -581.05 & 1051.03 & 220.27 \\
\hline 2018 & 2146.77 & -875.47 & 1099.99 & 171.31 \\
\hline 2019 & 2504.52 & $\begin{array}{c}- \\
1233.2\end{array}$ & 1151.07 & 120.23 \\
\hline
\end{tabular}
menjadi semakin lama. Berikut ini ditampilkan

\begin{tabular}{|c|c|c|c|c|}
\hline & & 2 & & \\
\hline 2020 & 2939.72 & $\begin{array}{c}- \\
1668.4 \\
2\end{array}$ & 1204.44 & 66.86 \\
\hline 2021 & 3469.71 & $\begin{array}{c}- \\
2198.4 \\
1\end{array}$ & 1260.48 & 10.82 \\
\hline 2022 & 4115.78 & $\begin{array}{c}- \\
2844.4 \\
8\end{array}$ & 1319.55 & -48.25 \\
\hline 2023 & 4903.99 & $\begin{array}{c}- \\
3632.6 \\
9\end{array}$ & 1382.04 & -110.74 \\
\hline
\end{tabular}
ketersediaan energi mulai tahun 2009.

Tabel 6. Tabel Ketersediaan Energi Di Sulawesi

Dari tabel di atas dapat dilihat, bahwa surplus energi berdasarkan proyeksi menggunakan DKL 3.01 sampai tahun 2015. Sedangkan surplus energi berdasarkan proyeksi menggunakan regresi linear sampai tahun 2021

\section{ANALISA PEMBANGUNAN PEMBANGKIT LISTRIK DITINJAU DARI ASPEK LINGKUNGAN}

Dalam pembangunan suatu pembangkit listrik, aspek lingkungan harus tetap diperhatikan. Sesuai dengan konsep pembangunan berkelanjutan yang dicanangkan pemerintah dan untuk memperkirakan besar dan pentingnya dampak yang mungkin terjadi, maka perlu dilakukan Analisa Mengenai Dampak Lingkungan (AMDAL). Aspek-aspek tersebut meliputi:

a. Tahap Pra Konstruksi

b. Tahap Konstruksi

c. Tahap Operasi

d. Tahap Pasca Operasi

\section{Thap pra Konstruksi}

Dampak kegiatan pembangunan pembangkit pada tahap pra konstruksi antara lain ketika diadakan survei awal, presepsi masyarakat bisa turun. Hal ini disebabkan karena kegiatan survei dan ketidaktahuan masyarakat terhadap rencana kegiatan menyebabkan masyarakat berfikir negatif terhadap rencana proyek. Untuk mengatasi hal tersebut maka hal yang perlu dilakukan adalah mengadakan penyuluhan kepada masyarakat mengenai rencana kegiatan 
yang akan dilaksanakan dengan secara rutin dan mengadakan pendekatan teradap ulama dan tokoh-tokoh masyarakat setempat.

\section{Tahap Konstruksi}

Pada tahap konstruksi akan terjadi penurunan kualitas udara berupa meningkatnya kandungan debu akibat transportasi bahan bangunan, peralatan dan pekerja di sepanjang jalan yang dilewati truk/sarana transportasi menuju ke lokasi proyek. Jika lokasi pembangkit di sungai yaitu untuk pembangunan PLTM, maka dampak yang lain adalah terjadi perubahan mendasar pada biota air, khususnya benthos, nekhton dan plankton. Ini akibat dari kerusakan pada bagian sungai. Selain itu, dengan adanya pembangunan pembangkit listrik, maka akan tercipta lapangan kerja selama pembagunan.

\section{Tahap Operasi}

Pembahasan tentang aspek lingkungan pada tahap operasi PLTM Mobuya 3 MW.

a. Ramah Ligkungan

PLTM Mobuya ini tidak mengeluarkan emisi atau gas buangan seperti pembangkit yang menggunakan bahan bakar fosil, sehingga pembangkit ini ramah terhadap lingkungan.

b. Pembangkit Multi Fungsi

Selain berfungsi pembangkit tenaga listrik, PLTM Mobuya ini juga berfungsi untuk menyediakan air irigasi, pengendalian banjir, perikanan dan juga pariwisata. Pada PLTM ini, pembangkitan tenaga listriknya perlu dikoordinasikan dengan keperluan irigasi untuk ladang dan tegalan di sekitarnya. Dari segi pengendalian banjir, PLTM harus dapat diatur air keluarnya sehingga pada saat banyak hujan tidak timbul banjir di sisi hilir.

\section{Tahap pasca Operasi}

Pada tahap ini dampak yang ditimbulkannya antara lain adanya pemutusan hubungan kerja dari para pekerja yang sebelumnya telah bekerja untuk membangun pembangkit tersebut. Kemudian dampak yang lain adalah tanah atau lahan bekas pembangkit menjadi tanah yang tandus atau gersang sehingga perlu untuk segera dilakukan pengelolaan tanah atau lahan tersebut.

\section{KESIMPULAN}

Berdasarkan hasil perhitungan dan analisa yang telah dilakukan dapat diambil beberapa kesimpulan antara lain :

1. Potensi tenaga air yang dibangkitkan sungai Poigar untuk pembangunan PLTM Mobuya di Bolaang Mangondow Sulawesi Utara dengan menggunakan ketinggian sekitar $80 \mathrm{~m}$ dan debit rata-rata saluran dengan pembangkit beroperasi maksimum selama 270 hari sebesar $5,21 \mathrm{~m} 3 / \mathrm{s}$ adalah 3 MW.

2.Pembangunan PLTM Mobuya ini tidak mengeluarkan emisi atau gas buangan seperti pembangkit yang menggunakan bahan bakar fosil tetapi awal pembangunanya merusak ekosistem sungai

3. Setelah pembangkit PLTM Mobuya dibangun dapat mengurangi krisis listrik di Sulawesi Utara maksimal samapai tahun 2021 sehingga diharapkan dapat meningkatkan rasio elektrifikasi di sana yang akan berdampak pada peningkatan IPM masyarakat di sekitarnya

\section{DAFTAR PUSTAKA}

[1] 2008. Pemerintah Provinsi Sulawesi Utara, URL: http://www.sulut.go.id.

[2] 2008 Statistik PLN, URL: http:// www. pln.co.id

[3] Artono Arismunandar, Susumu Kuwahara, Buku Pegangan Teknik Tegangan Tenaga Listrik Jilid I: Pembangkitan dengan Tenaga Air, PT Pradnya Paramita, Jakarta, 2000.

[4] Hadi Susilo, Pengembangan Sumber Daya Air, Pusat Pengembangan Bahan Ajar UMB, Jakarta, 2008.

[5] Guide on How to Develop a Small Hydropower Plant, European Small Hydropower Association-ESHA, Inggris, 2004.

[6] Fitriani Sagala. 2008. Analisis Regresi Berganda Terhadap Faktor-Faktor Yang Mempengaruhi Laju Inflasi.Medan : Universitas Sumatera Utara 
[7] 2008, Badan Pusat Statistik, URL: http:// www.sulut.bps.go.id

[8] 2008. Direktorat Sumber Daya Air, Dinas

Pekerjaan Umum, URL:

http://www.pu.go.id/ 